Supplement of Atmos. Chem. Phys., 22, 441-463, 2022

https://doi.org/10.5194/acp-22-441-2022-supplement

(C) Author(s) 2022. CC BY 4.0 License.

(c) (1)

Atmospheric

Chemistry

and Physics

Supplement of

\title{
Atmospheric rivers and associated precipitation patterns during the ACLOUD and PASCAL campaigns near Svalbard (May-June 2017): case studies using observations, reanalyses, and a regional climate model
}

Carolina Viceto et al.

Correspondence to: Carolina Viceto (carolinaviceto@ua.pt) and Irina Gorodetskaya (irina.gorodetskaya@ua.pt)

The copyright of individual parts of the supplement might differ from the article licence. 

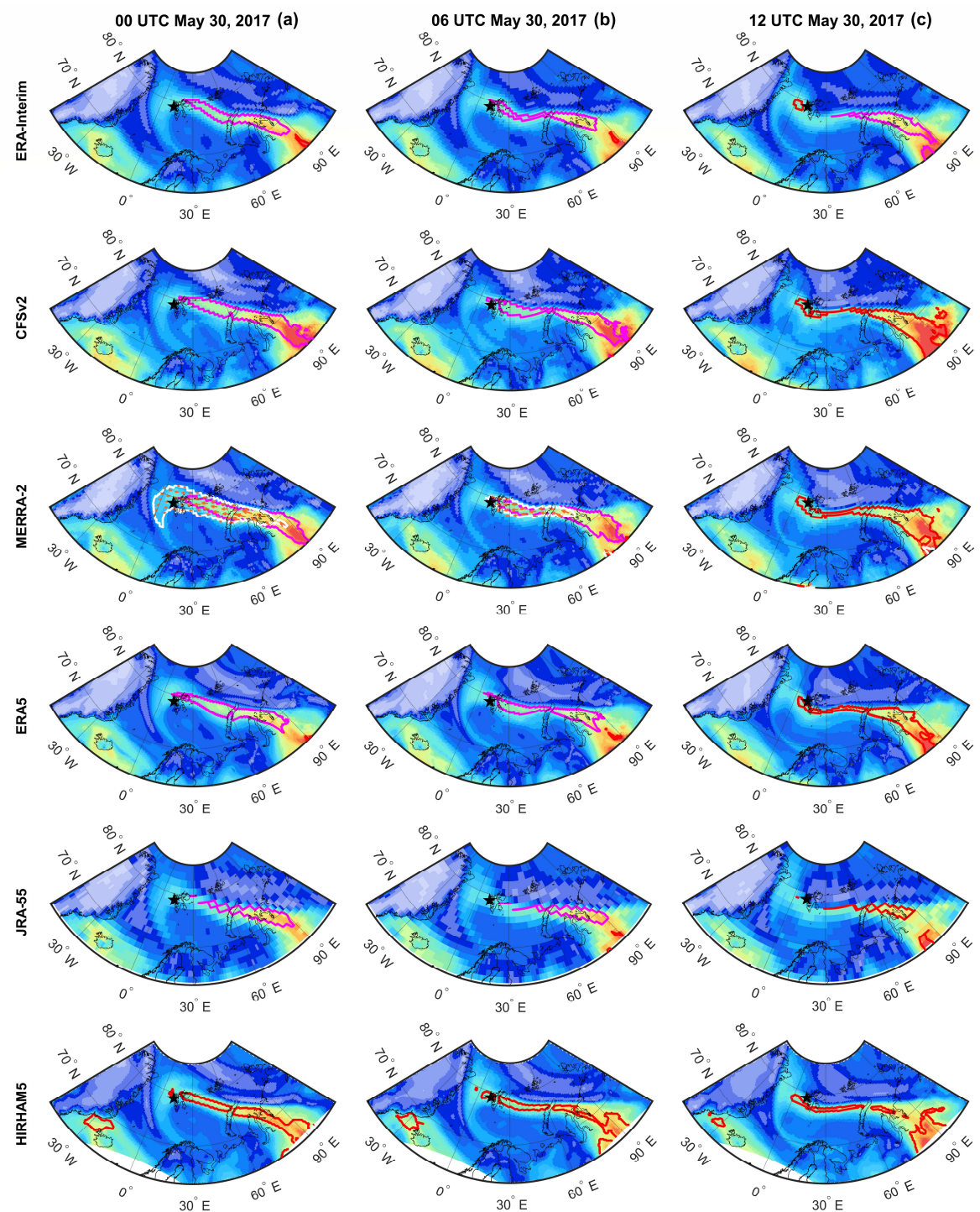

$\underline{\underline{g}}$
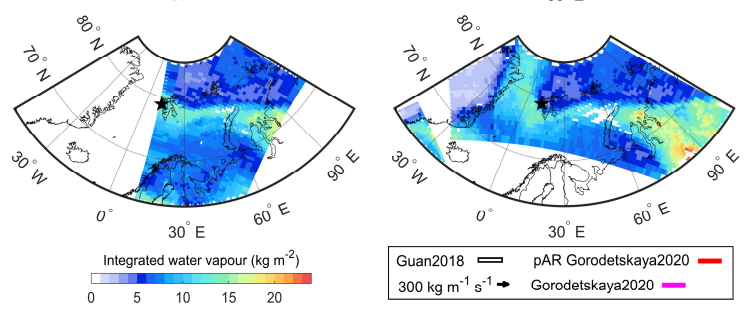

Figure S1. Maps of integrated water vapour (IWV, $\mathrm{kg} \mathrm{m}^{-2}$, colour shading) for the 30 May 2017 event, 6 hours before the IWV peak (a), during the peak (b) and 6 hours after the peak (c) based on reanalyses (ERA-Interim, CFSv2, MERRA-2, ERA5, JRA-55), HIRHAM5 model and IASI observations. Magenta line shows AR shape (based on Gorodetskaya2020) and red line shows the shape of pARs (IWV $\geq I W V_{\text {thres, }}$ based on Gorodetskaya2020). White line shows AR shape (based on Guan2018) and black arrows show integrated vapour transport (IVT, $\mathrm{kg} \mathrm{m}^{-1} \mathrm{~s}^{-1}$ ), both based only on MERRA-2 reanalysis. Black star shows Ny-Ålesund location. 

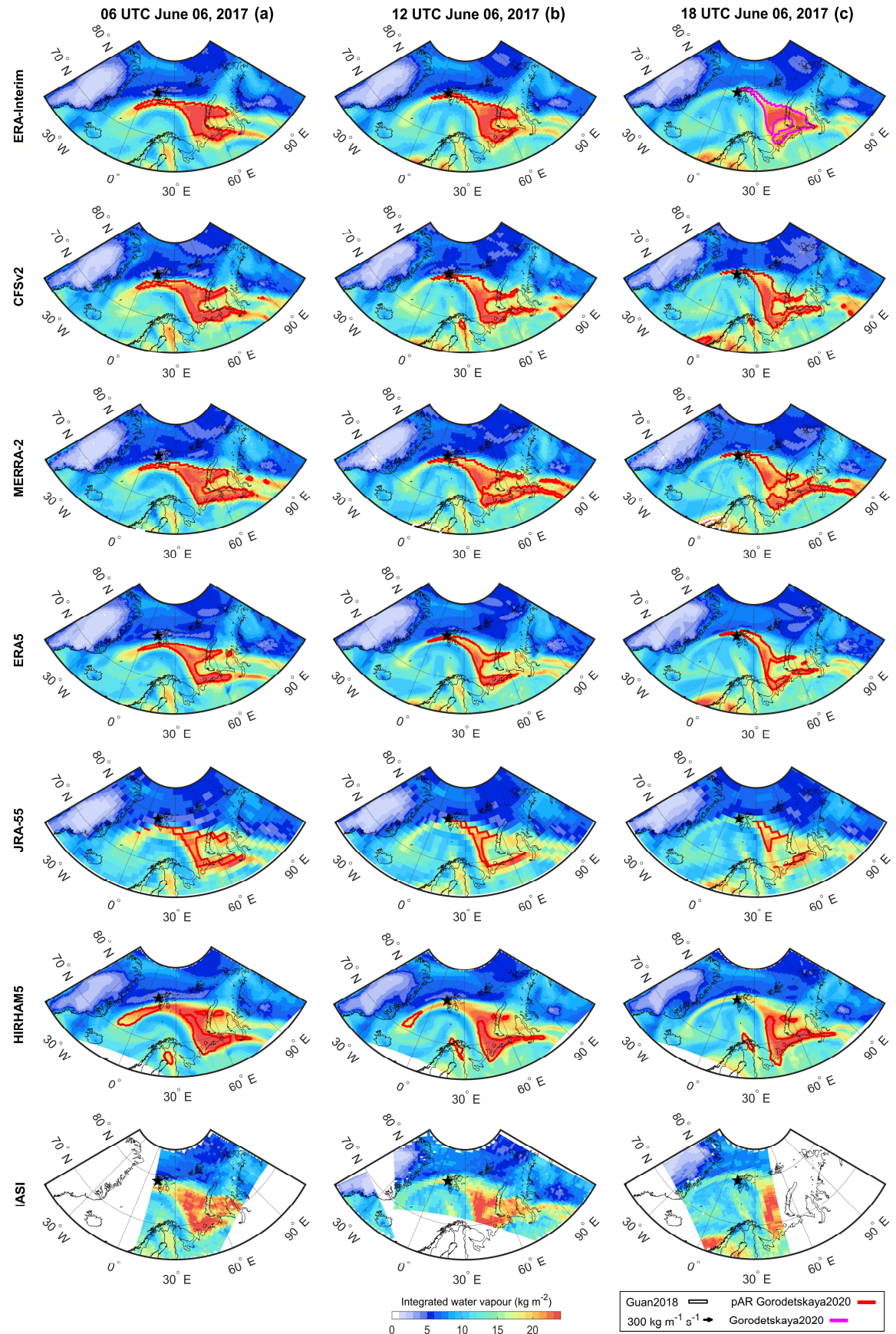

Figure S2. Same as Figure S1, but for the 6 June 2017 event. 

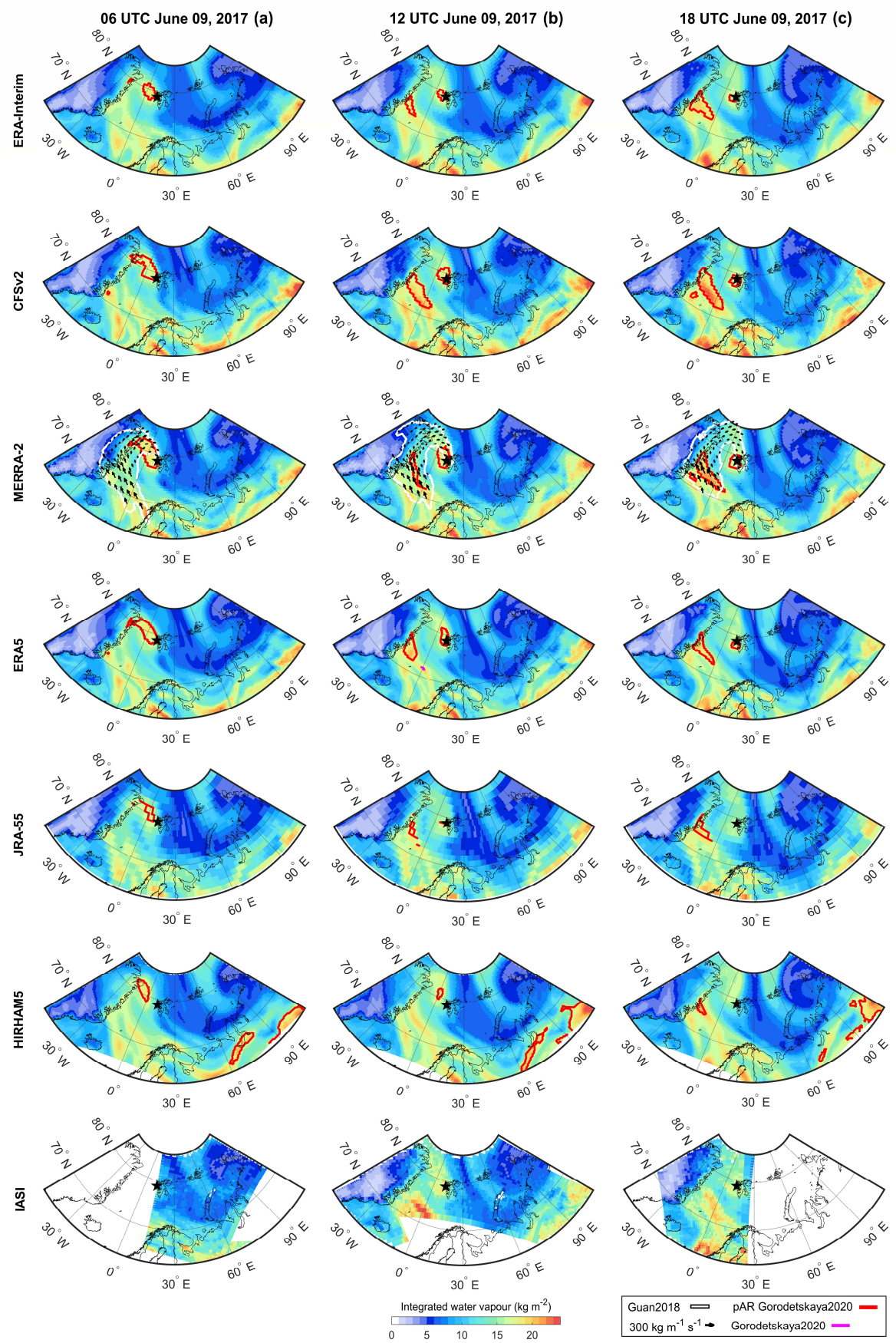

Figure S3. Same as Figure S1, but for the 9 June 2017 event. 
(a)

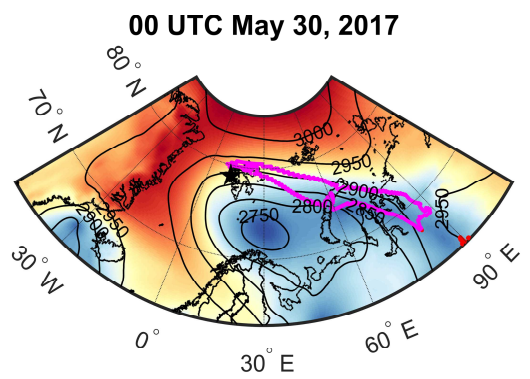

(b)

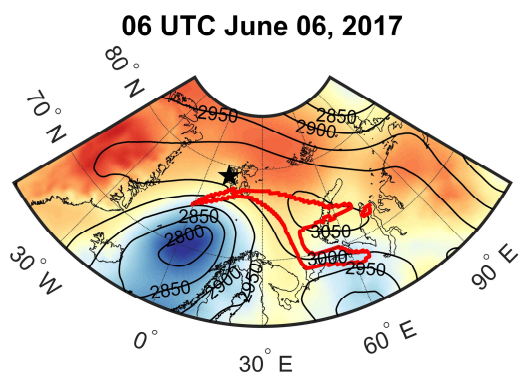

(c)

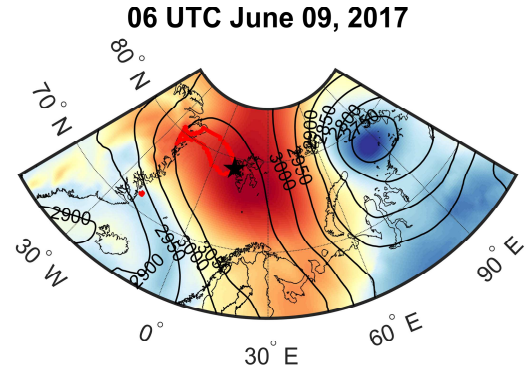

06 UTC May 30, 2017

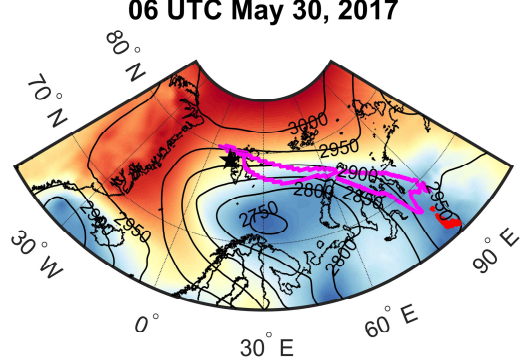

12 UTC June 06, 2017

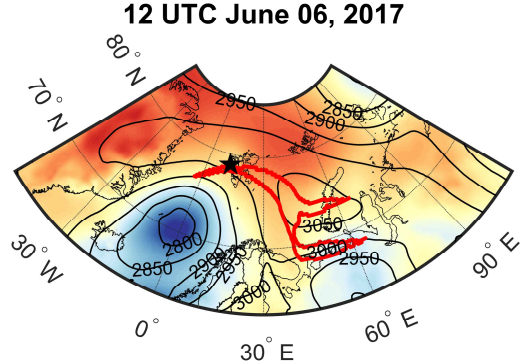

12 UTC June 09, 2017

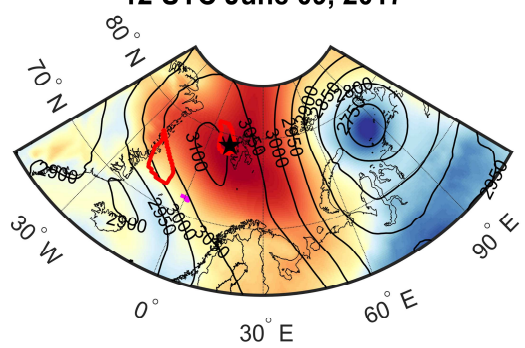

Mean sea level pressure (hPa)
12 UTC May 30, 2017

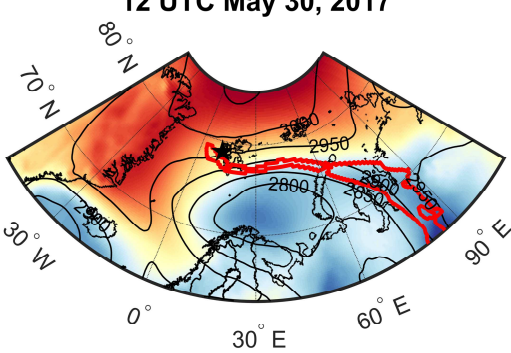

18 UTC June 06, 2017

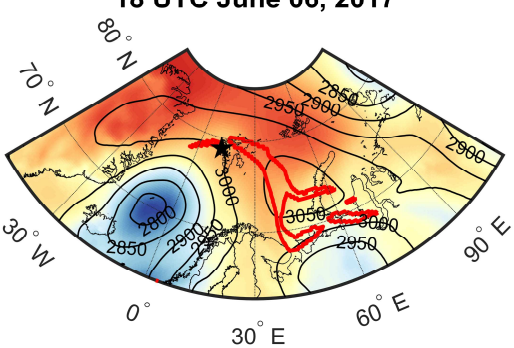

18 UTC June 09, 2017 $\infty^{\circ}$

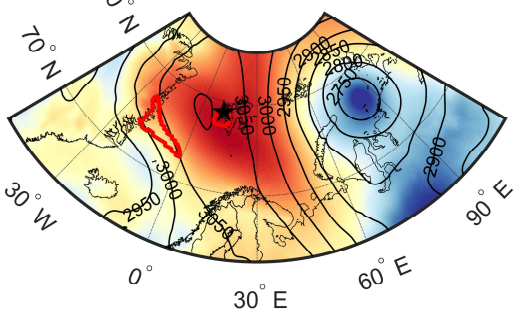

pAR Gorodetskaya2020
Gorodetskaya2020

Figure S4. Maps of mean sea level pressure ( $\mathrm{hPa}$, colour shading) and geopotential height at $700 \mathrm{hPa}$ ( $\mathrm{m}$, contours) based on ERA5 reanalysis during the 30 May event [first row, (a)], 6 June event [second row, (b)] and 9 June event [third row, (c)]. Magenta line shows AR shape (based on Gorodetskaya2020) and red line shows the shape of pARs (IWV $\geq I W V_{\text {thres, }}$ based on Gorodetskaya2020). Black star shows NyÅlesund location. 
(a)

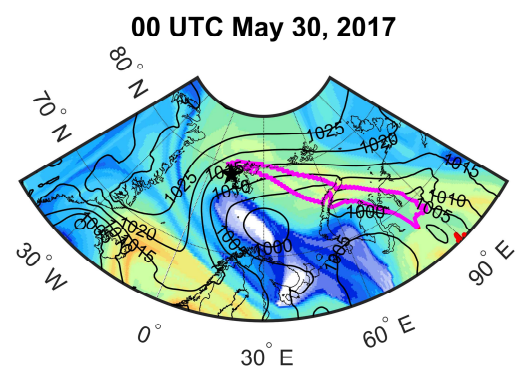

(b)

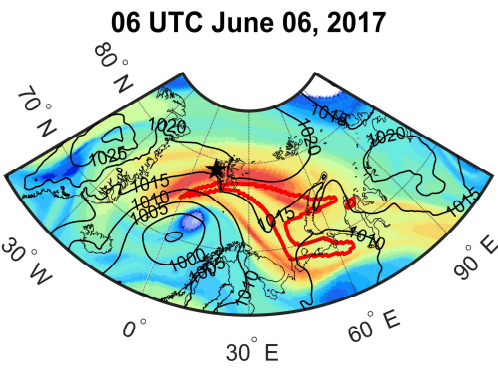

(c)

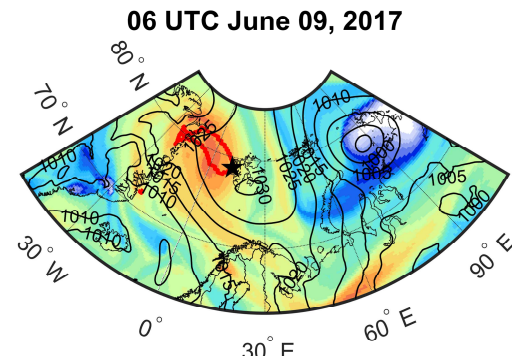

06 UTC May 30, 2017

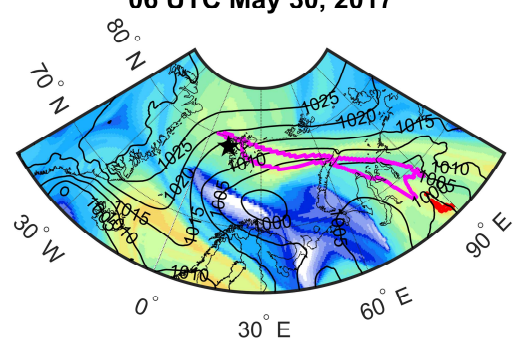

12 UTC June 06, 2017

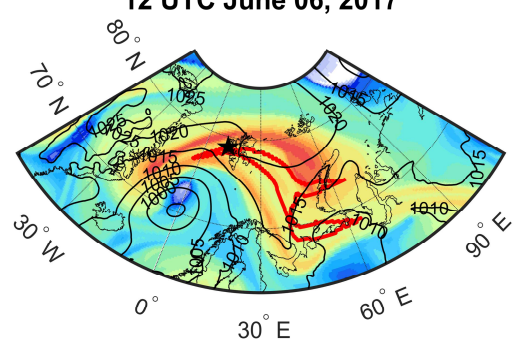

12 UTC June 09, 2017

$\therefore$.

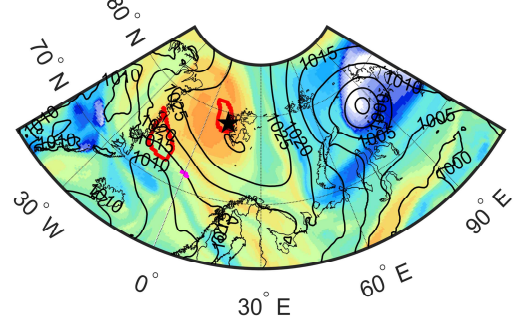

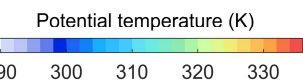

12 UTC May 30, 2017

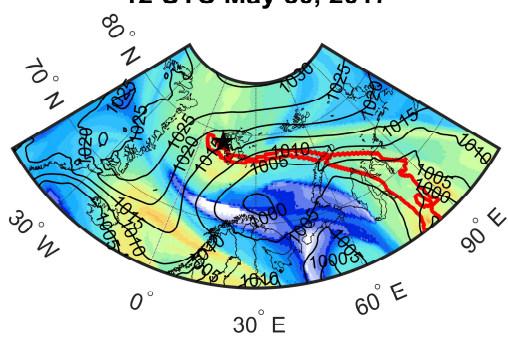

18 UTC June 06, 2017

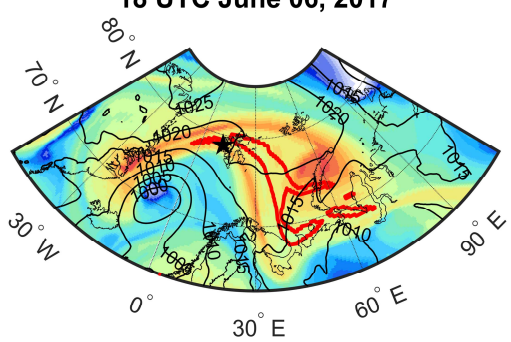

18 UTC June 09, 2017

\%。

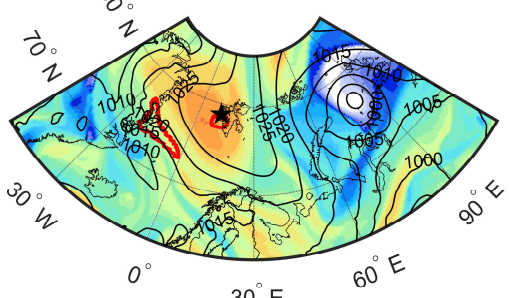

pAR Gorodetskaya2020
Gorodetskaya2020

Figure S5. Maps of potential temperature at 2 PVU (K, colour shading) and mean sea level pressure (hPa, contours) based on ERA5 reanalysis during the 30 May event [first row, (a)], 6 June event [second row, (b)] and 9 June event [third row, (c)]. Magenta line shows AR shape (based on Gorodetskaya2020) and red line shows the shape of pARs (IWV $\geq I W V_{\text {thres, }}$, based on Gorodetskaya2020). Black star shows Ny-Ålesund location. 

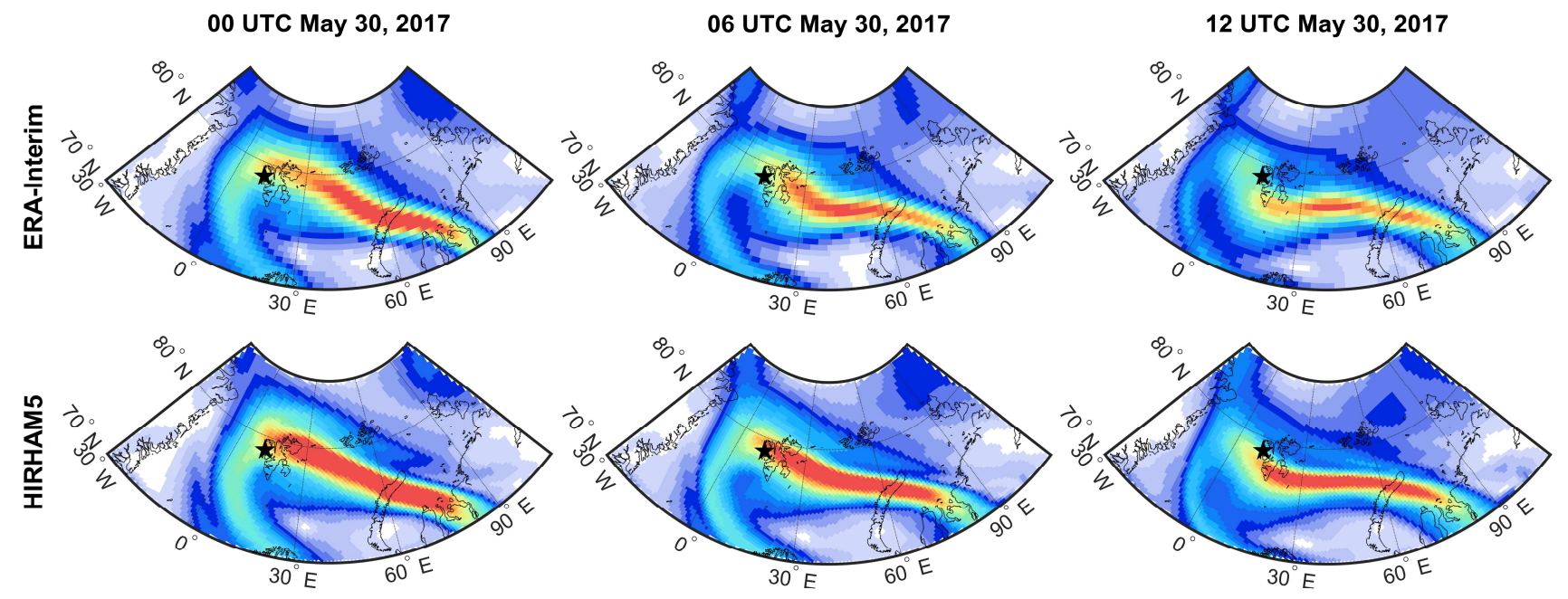

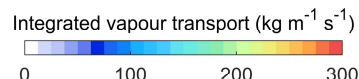

Figure S6. Maps of integrated vapour transport $\left(\mathrm{kg} \mathrm{m}^{-1} \mathrm{~s}^{-1}\right.$, shading) based on ERA-Interim reanalysis (first row) and HIRHAM5 model (driven by ERA-Interim fields) (second row) during the 30 May 2017 event. Black star shows Ny-Ålesund location.
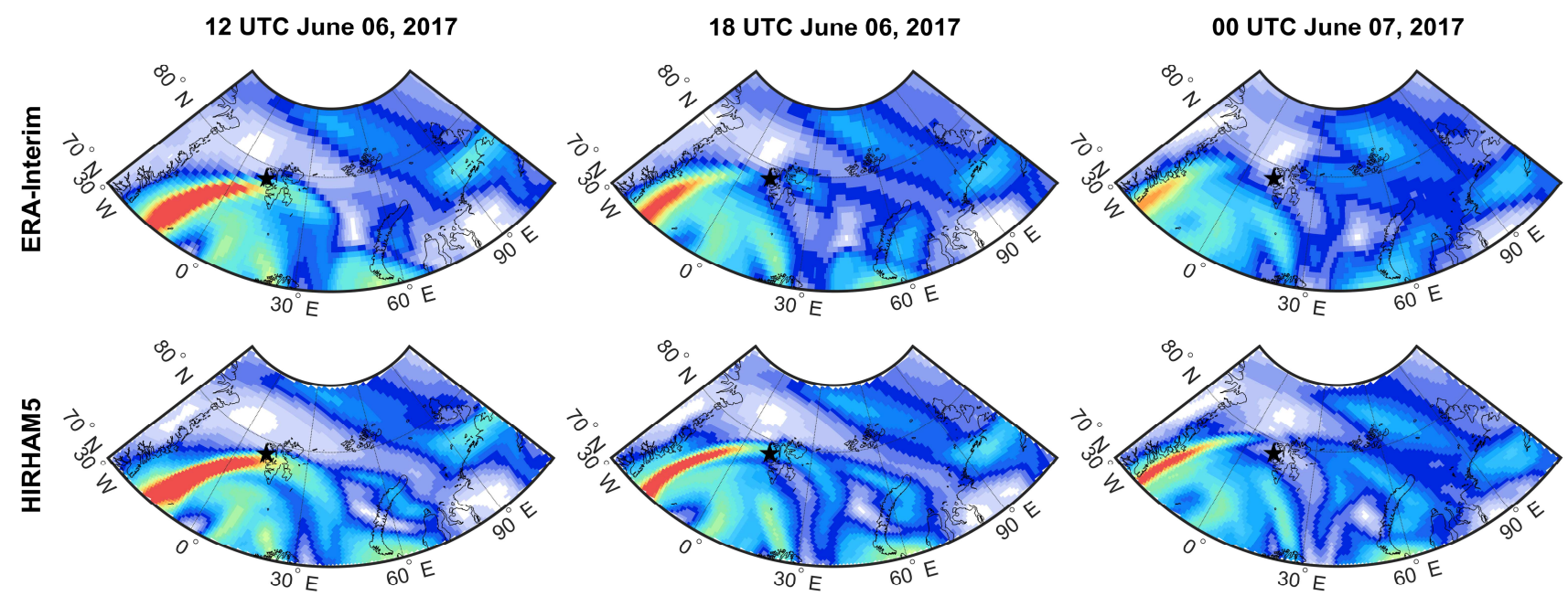

Integrated vapour transport $\left(\mathrm{kg} \mathrm{m}^{-1} \mathrm{~s}^{-1}\right)$

$0 \quad 100 \quad 200 \quad 300$

Figure S7. Same as Figure S6, but for the 6 June 2017 event. 
(a) 00 UTC May 30, 2017

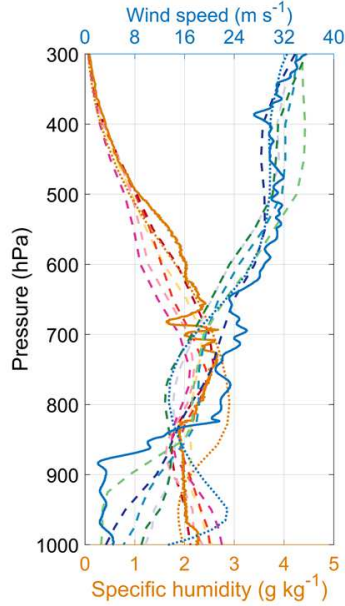

(b)

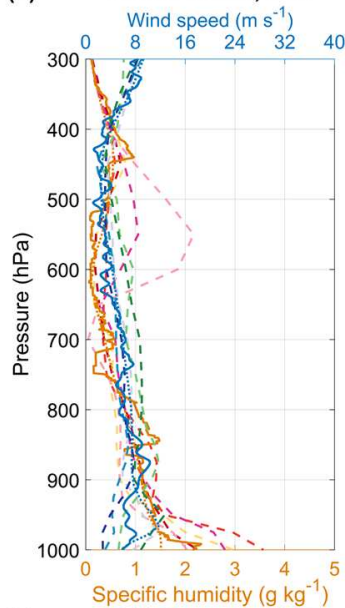

(c)
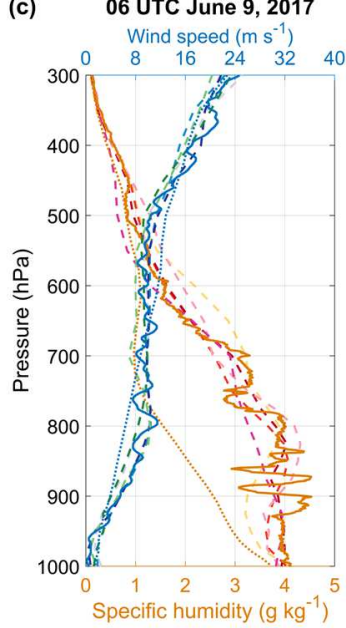

06 UTC May 30, 2017

Wind speed $\left(\mathrm{m} \mathrm{s}^{-1}\right)$

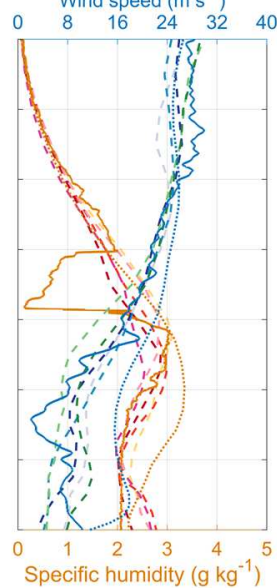

12 UTC June 6, 2017
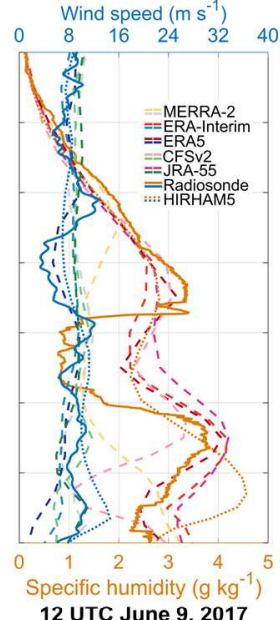

12 UTC June 9, 2017
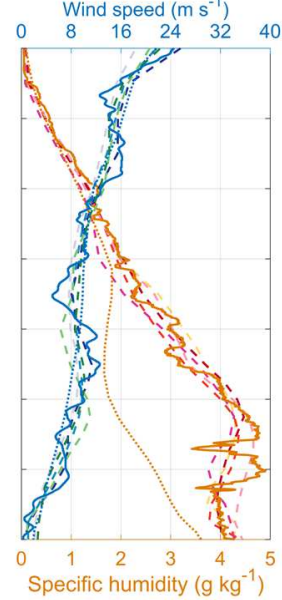

12 UTC May 30, 2017

Wind speed $\left(\mathrm{m} \mathrm{s}^{-1}\right)$
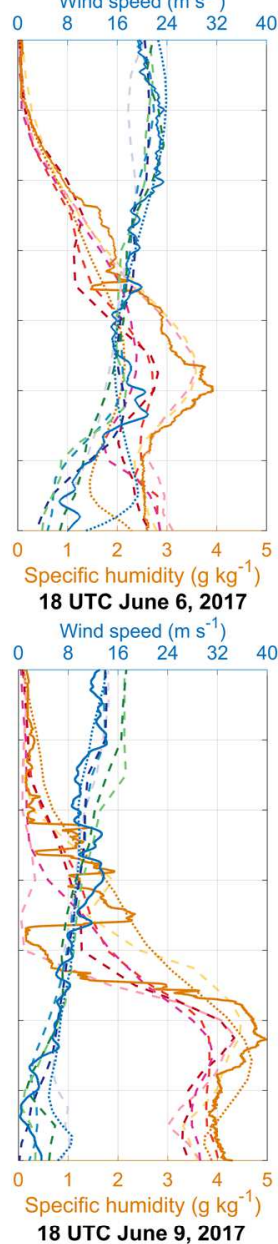

Wind speed $\left(\mathrm{m} \mathrm{s}^{-1}\right)$

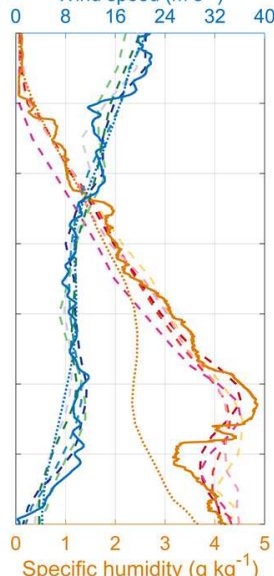

Figure S8. Vertical profiles of specific humidity ( $\mathrm{g} \mathrm{kg}^{-1}$, pink/orange colours) and wind speed ( $\mathrm{m} \mathrm{s}^{-1}$, blue/green colours) at Ny-Ålesund based on radiosonde (solid lines), reanalyses (ERA-Interim, ERA5, CFSv2, JRA-55, MERRA-2, dashed lines) and HIRHAM5 model (dotted lines), during 30 May event [first row, (a)], 6 June event [second row, (b)] and 9 June event [third row, (c)]. 
(a)

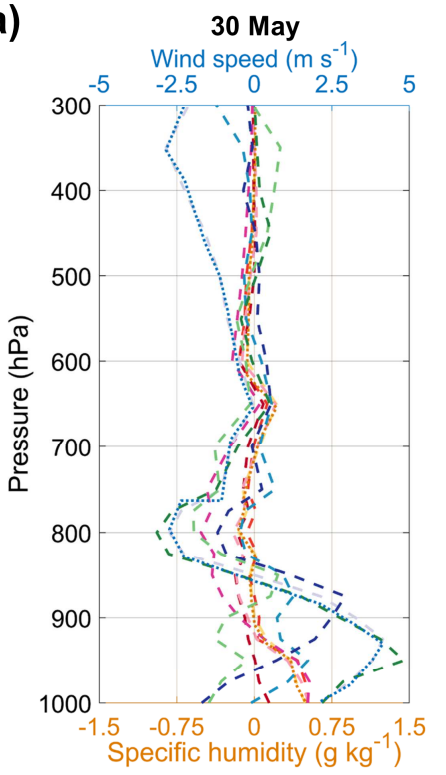

(b)

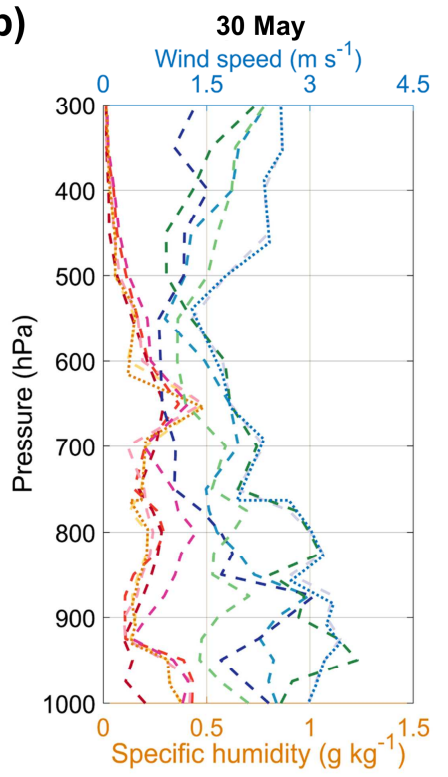

6 June

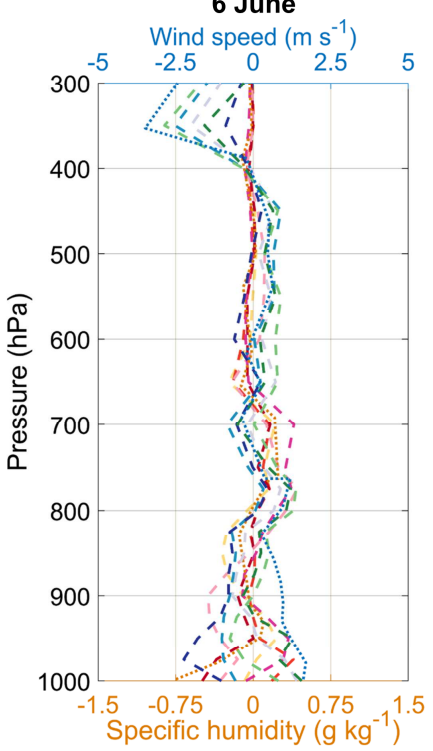

6 June

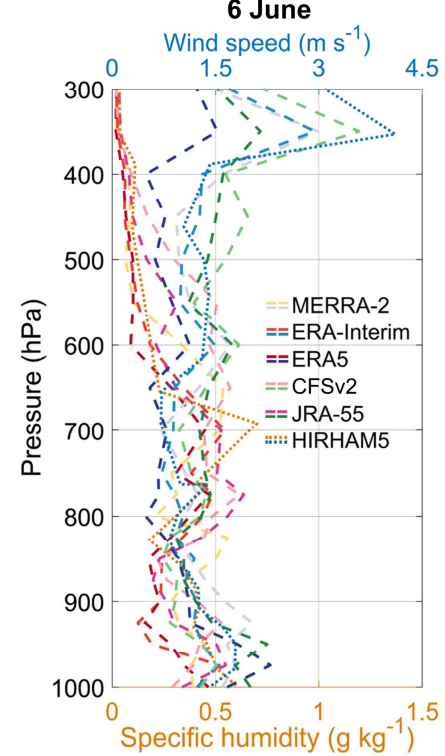

9 June

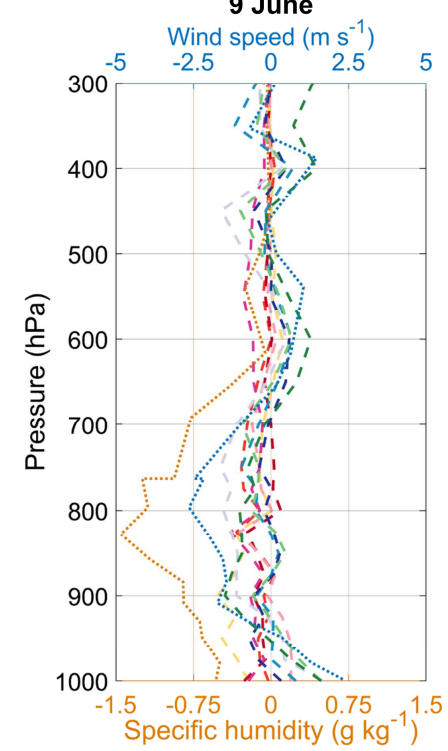

9 June

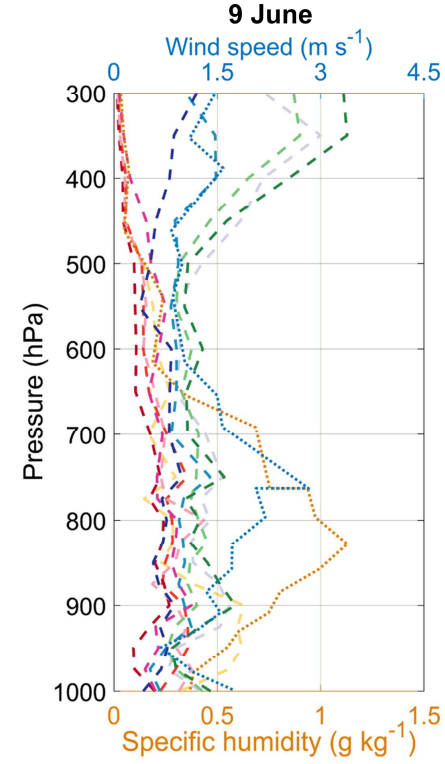

Figure S9. Vertical profiles of specific humidity ( $\mathrm{g} \mathrm{kg}^{-1}$, pink/orange colours) and wind speed ( $\mathrm{m} \mathrm{s}^{-1}$, blue/green colours) bias [first row, (a)] and RMSE [second row, (b)] at Ny-Ålesund based on reanalyses (ERA-Interim, ERA5, CFSv2, JRA-55, MERRA-2, dashed lines) and HIRHAM5 model (dotted lines) compared to the radiosondes (reference, 6 hours temporal resolution), during 48 hours periods (24 hours before and after the event reached Ny-Ålesund) for the 30 May event (first column), 6 June event (second column) and 9 June event (third column). 

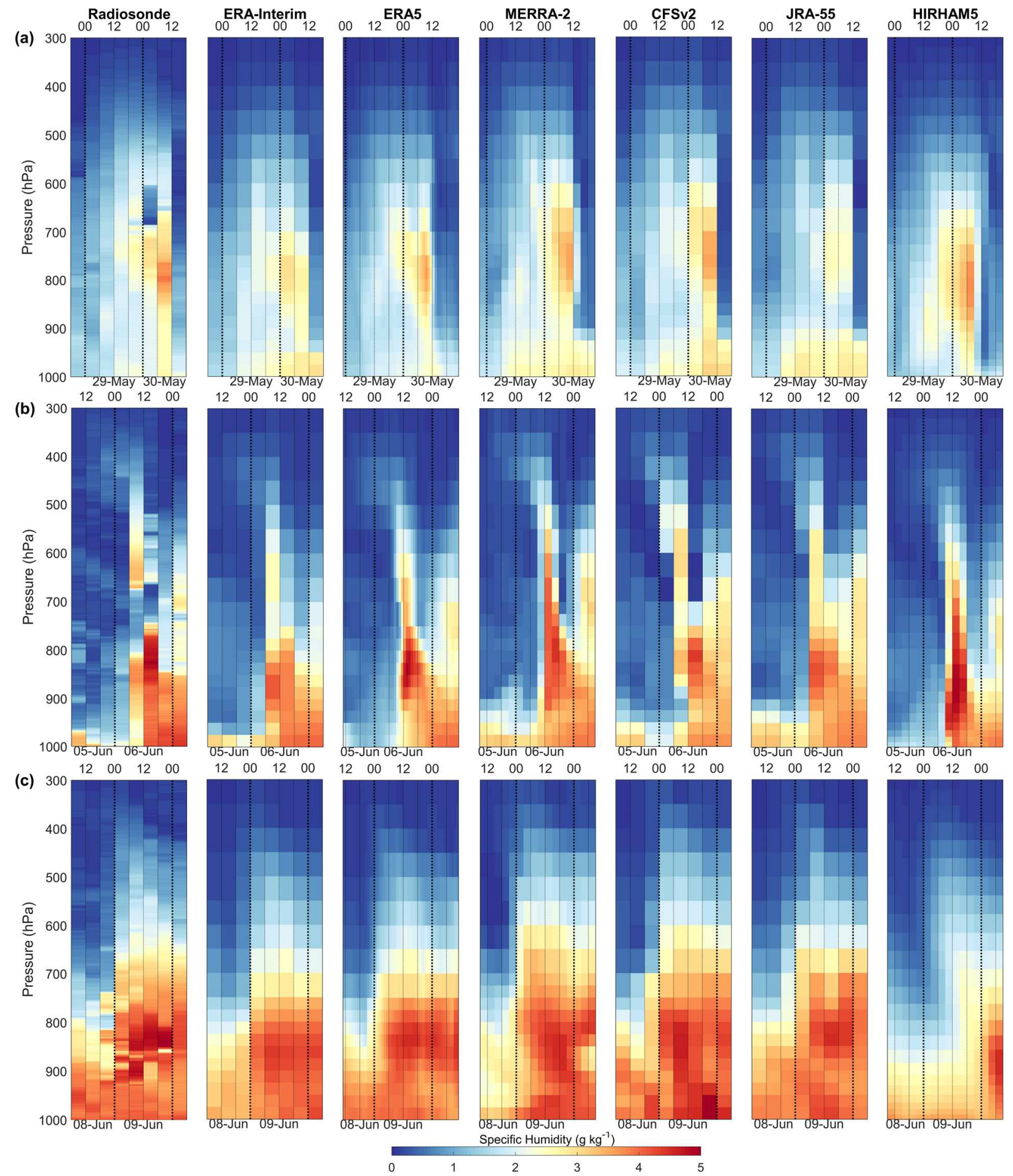

Figure S10. Temporal evolution of the vertical profiles of specific humidity $\left(\mathrm{g} \mathrm{kg}^{-1}\right)$ based on radiosondes, reanalyses (ERA-Interim, ERA5, MERRA-2, CFSv2, JRA-55), and HIRHAM5 model, during 30 May 2017 event [first row, (a)], 6 June 2017 event [second row, (b)] and 9 June event [third row, (c)], at Ny-Ålesund. Time steps on the x-axis mark the end of observations/reanalyses/model. 

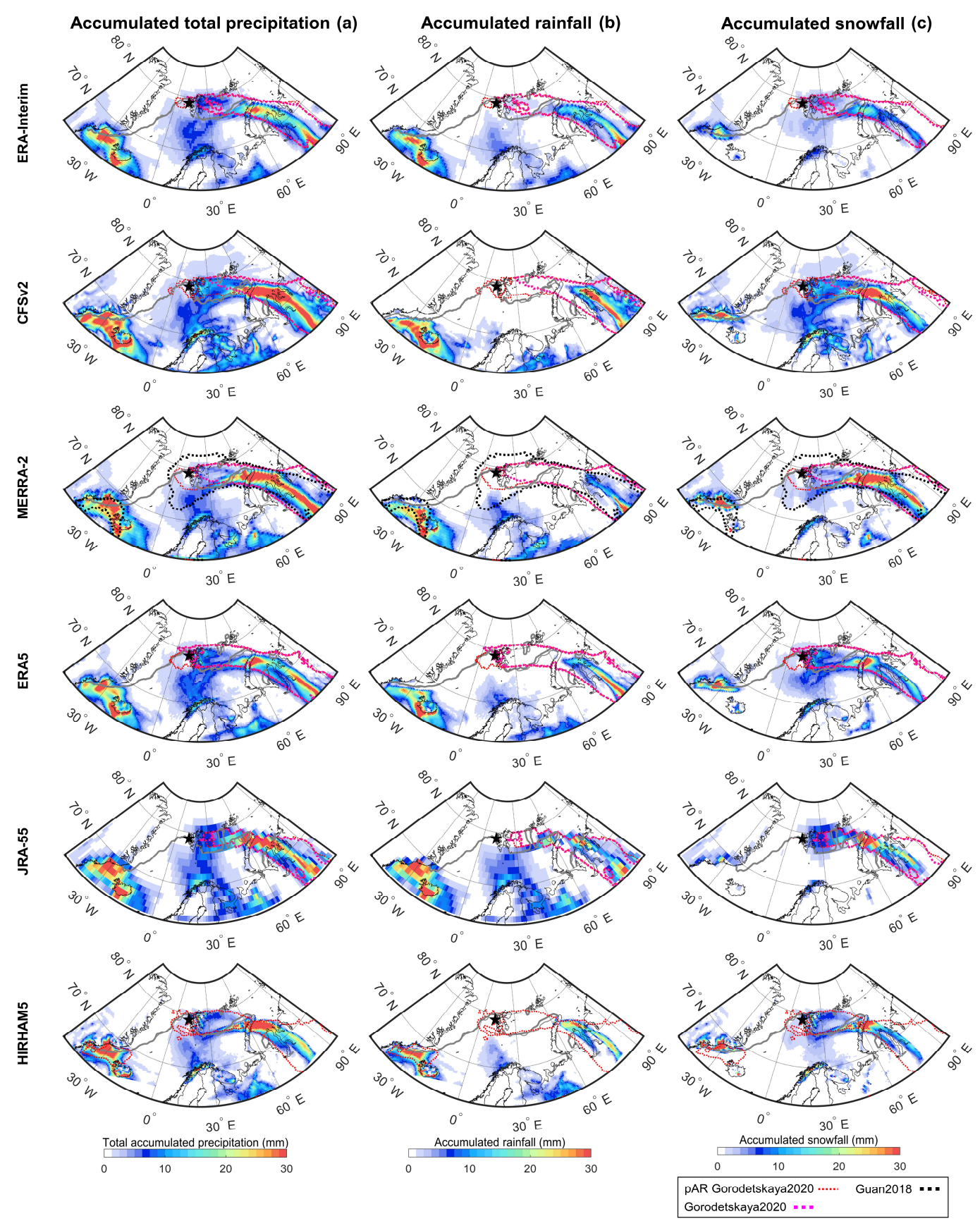

Figure S11. Maps of the total accumulated precipitation [mm, first column, (a)], accumulated rainfall [mm, second column, (b)] and accumulated snowfall [mm, third column, (c)] for the 30 May event during a 48 hours period (24 hours before and after the event reached Ny-Ålesund, shown by black star) based on reanalyses (ERA-Interim, CFSv2, MERRA-2, ERA5, JRA-55) and HIRHAM5 model. Grey lines show the sea-ice fraction using a 15\% threshold (thin line represents 24 hours before the event and thick line 24 hours after the event). Magenta and red lines show the AR and pAR shapes, respectively, based on Gorodetskaya2020. Black line shows the AR shape based on Guan2018 (available only for MERRA-2). The AR shape lines here encompass the total area of the ARs/pARs during the 48 hours period. 

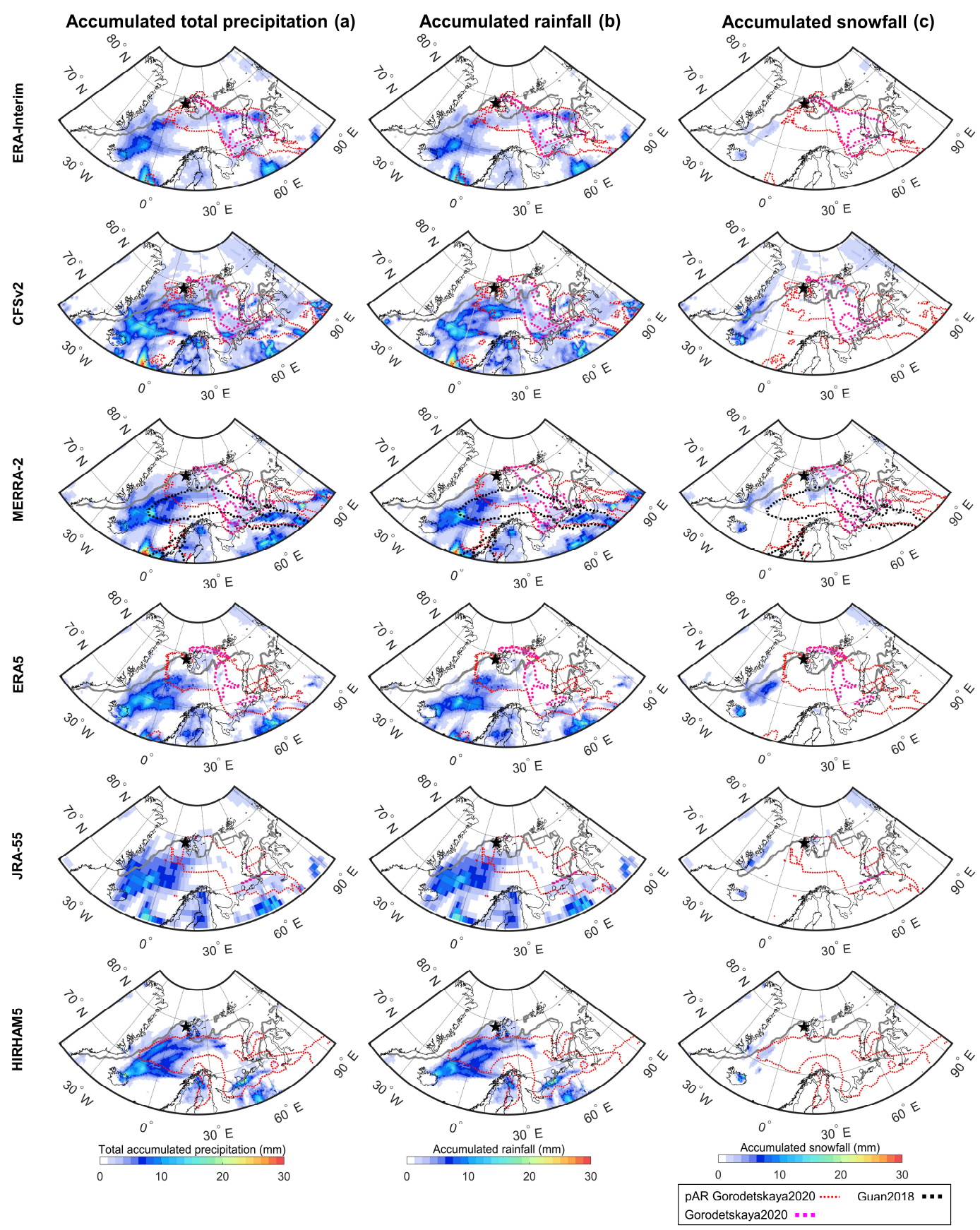

Figure S12. Same as Figure S11, but for the 6 June 2017 event. 

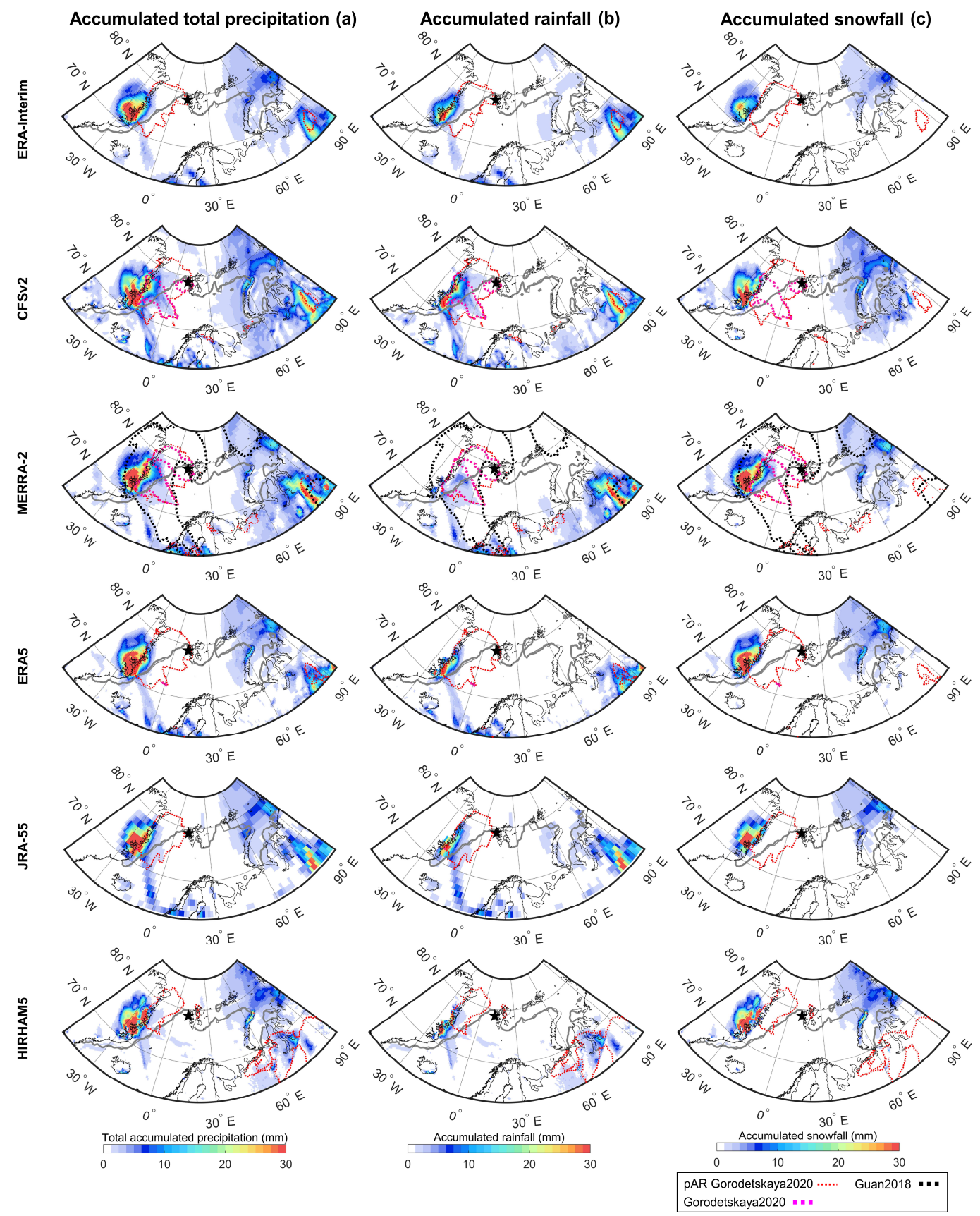

Figure S13. Same as Figure S11, but for the 9 June 2017 event. 
NOAA HYSPLIT MODEL

Backward trajectories ending at 0600 UTC 30 May 17 GFSG Meteorological Data

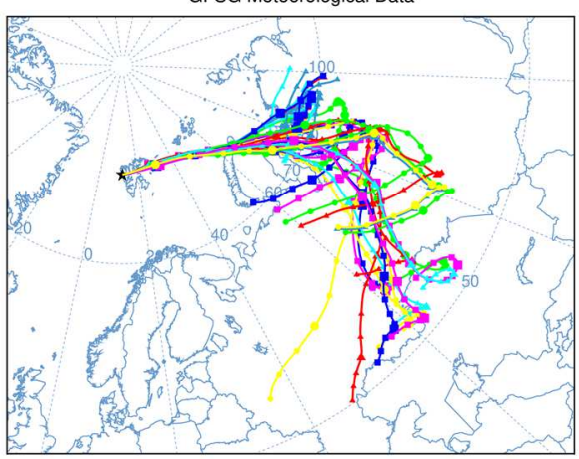
Ories ending at 1200 UTC 06 Jun 17 GFSG Meteorological Data

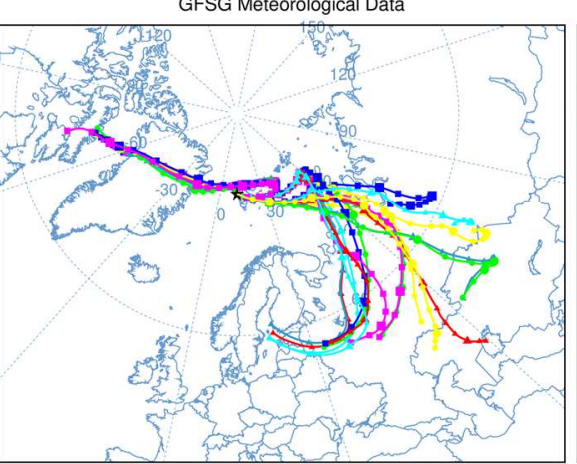

NOAA HYSPLIT MODEL

Backward trajectories ending at 1200 UTC 09 Jun 17 GFSG Meteorological Data

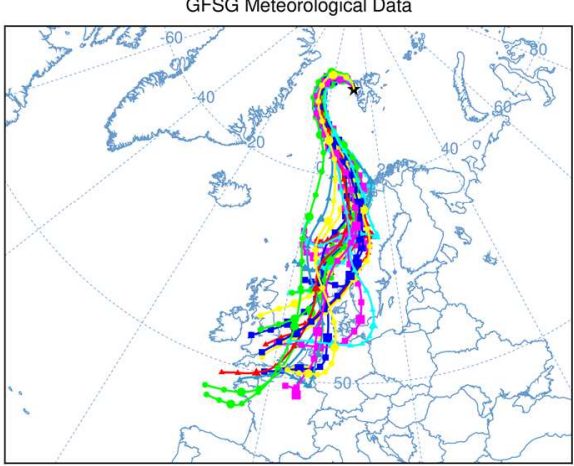

Figure S14. Computed ensemble of back trajectories (different colours) at 6 hours intervals (markers) ending at 06 UTC 30 May (left panel), 12 UTC 6 June (middle panel) and 12 UTC 9 June (right panel), at $800 \mathrm{hPa}$, from Ny-Ålesund (black star), using HYSPLIT model. 
Table S1. Integrated water vapour (IWV, $\mathrm{kg} \mathrm{m}^{-2}$ ) and integrated vapour transport (IVT, $\mathrm{kg} \mathrm{m}^{-1} \mathrm{~s}^{-1}$ ) bias and RMSE during the 24 hours before and after the IWV peak at Ny-Ålesund (48-hours period), for the reanalyses (ERA-Interim, ERA5, MERRA-2, CFSv2, JRA-55), HIRHAM5 model and observations (HATPRO, GNSS and IASI), using the radiosondes as a reference (6 hours temporal resolution).

\begin{tabular}{|c|c|c|c|c|c|c|c|}
\hline \multirow{2}{*}{ Variable } & \multicolumn{2}{|c|}{ 30 May } & \multicolumn{2}{c|}{ 6 June } & \multicolumn{2}{c|}{ 10 June } \\
\cline { 2 - 8 } & & RMSE & Bias & RMSE & Bias & RMSE & Bias \\
\hline \multirow{2}{*}{ Era-Interim } & IWV & 1.1 & 0.2 & 1.1 & 0.2 & 0.6 & -0.5 \\
\cline { 2 - 8 } & IVT & 28.8 & 2.2 & 8.9 & 2.4 & 7.2 & -3.4 \\
\hline \multirow{2}{*}{ MERRA-2 } & IWV & 1.1 & -0.3 & 0.8 & -0.1 & 0.3 & -0.2 \\
\cline { 2 - 8 } & IVT & 23.2 & -1.1 & 3.5 & 0 & 3.9 & 0.2 \\
\hline \multirow{2}{*}{ CFSv2 } & IWV & 0.9 & 0.2 & 1.2 & 0 & 1.3 & -0.6 \\
\cline { 2 - 8 } & IVT & 24.2 & 3.9 & 18.5 & 9.3 & 12.2 & -9.2 \\
\hline \multirow{2}{*}{ JRA-55 } & IVT & 19.5 & -8.6 & 12.6 & 3.7 & 5.2 & -0.6 \\
\cline { 2 - 8 } & IWV & 1.5 & -1.1 & 1.4 & 0.6 & 1.2 & -0.9 \\
\hline \multirow{2}{*}{ HIRHAM5 } & 29.9 & -10.5 & 17.3 & 12.9 & 13.6 & -10.1 \\
\cline { 2 - 8 } & IWV & 5.2 & -0.2 & 4.9 & -0.2 & 11.9 & -3.5 \\
\hline HATPRO & IVT & 140.6 & 19.6 & 87.1 & 19.2 & 105.6 & -28.8 \\
\hline IWV & 0.4 & 0.3 & 1.3 & 0.3 & 0.9 & 0.6 \\
\hline IASI & IWV & 0.8 & -0.6 & 1.5 & -1.1 & 0.9 & -0.8 \\
\hline
\end{tabular}


Table S2. Integrated water vapour (IWV, $\mathrm{kg} \mathrm{m}^{-2}$ ) and integrated vapour transport (IVT, $\mathrm{kg} \mathrm{m}^{-1} \mathrm{~s}^{-1}$ ) amplitude and integrated during the event, and event duration (hours) of the AR shapes based on Gorodetskaya2020 (AR Go), of the shapes of pARs based on Gorodetskaya2020 (IWV $\geq$ IWV thres) (pAR Go) and the AR shapes based on Guan2018 (only for MERRA-2 reanalysis) (AR Gu) based on reanalyses (ERAInterim, ERA5, MERRA-2, CFSv2 and JRA-55) and HIRHAM5 model, at Ny-Ålesund, during 30 May, 6 June and 9 June 2017 events.

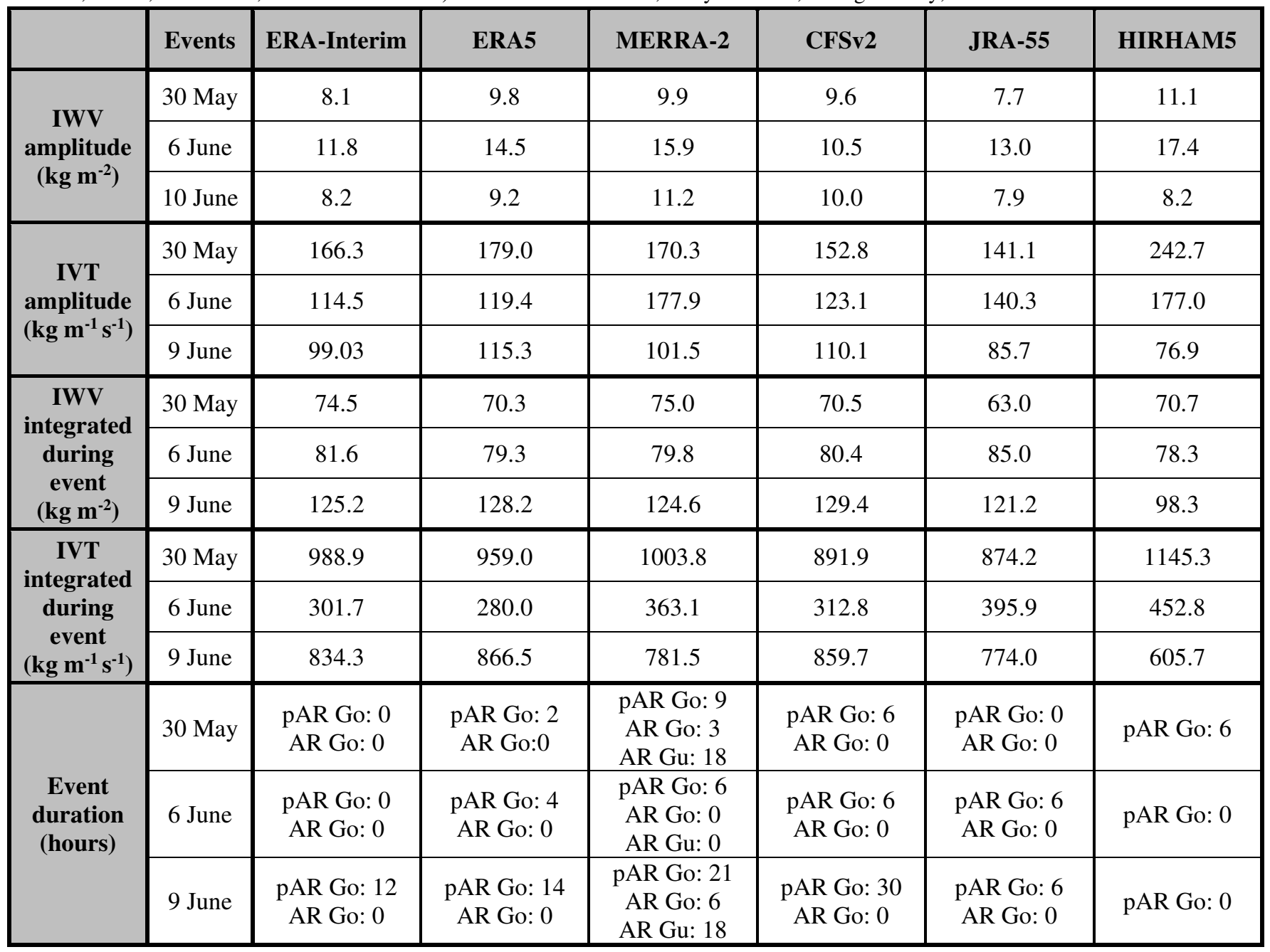

